\title{
Frequent electronic media communication with friends is associated with higher adolescent substance use
}

\author{
Rob Gommans • Gonneke W. J. M. Stevens • Emily Finne • \\ Antonius H. N. Cillessen - Meyran Boniel-Nissim • \\ Tom F. M. ter Bogt
}

Received: 5 August 2014/Revised: 9 November 2014/Accepted: 13 November 2014/Published online: 4 December 2014

(C) Swiss School of Public Health 2014

\begin{abstract}
Objectives This study investigated the unique associations between electronic media communication (EMC) with friends and adolescent substance use (tobacco, alcohol, and cannabis), over and beyond the associations of face-to-face (FTF) interactions with friends and the average level of classroom substance use.

Methods Drawn from the cross-national 2009/2010 Health Behaviour in School-aged Children (HBSC) study in The Netherlands, 5,642 Dutch adolescents $\left(M_{\text {age }}=\right.$ 14.29) reported on their substance use, EMC, and FTF interactions. Two-level multilevel analyses (participants nested within classrooms) were run.

Results Electronic media communication was positively associated with adolescent substance use, though significantly more strongly with alcohol $\left(\beta=0.15, \mathrm{SE}_{\beta}=0.02\right)$ than with tobacco $\left(\beta=0.05, \mathrm{SE}_{\beta}=0.02, t(5,180)=\right.$ $3.33, p<0.001)$ or cannabis use $\left(\beta=0.06, \mathrm{SE}_{\beta}=0.02\right.$, $t(5,160)=2.79, p<0.01)$. Further, EMC strengthened
\end{abstract}

This article is part of the special issue "Communication Technology, Media Use and the Health of Our Kids".

R. Gommans $(\bowtie)$ - G. W. J. M. Stevens - T. F. M. ter Bogt Centre for Child and Adolescent Studies, Utrecht University, Heidelberglaan 1, 3584 CS Utrecht, The Netherlands

e-mail: r.gommans@uu.nl

R. Gommans - A. H. N. Cillessen

Behavioural Science Institute, Radboud University, Nijmegen,

The Netherlands

E. Finne

Bielefeld University, Bielefeld, Germany

M. Boniel-Nissim

University of Haifa, Mount Carmel, Haifa, Israel several positive associations of FTF interactions and average classroom substance use with adolescent substance use.

Conclusions Electronic media communication was uniquely associated with substance use, predominantly with alcohol use. Thus, adolescents' EMC and other online behaviors should not be left unnoticed in substance use research and prevention programs.

Keywords Substance use - Adolescents ·

Electronic media communication .

Face-to-face interactions · Multilevel analysis

\section{Introduction}

Adolescents spend many hours interacting with peers (Dijkstra and Veenstra 2011). With the increase in electronic media communication (EMC; e.g., texting, instant messaging) among adolescents (Valkenburg and Peter 2010), the contexts important for adolescents' interactions with peers have expanded from the physical (offline) to the virtual (online) world (Brechwald and Prinstein 2011; Brown and Larson 2009). Adolescents use EMC frequently-complementary to or substituting for offline interactions - to communicate and to develop and maintain close relationships with their peers (Lenhart 2012; Lenhart and Madden 2007).

For example, $95 \%$ of American teenagers aged 12-17 use the internet (Purcell 2013), primarily for instant messaging (68\%) or social networking (65\%; Valkenburg and Peter 2010). In the US, 8- to 18-year-old adolescents spend an average of $2 \mathrm{~h}$ per day talking or texting on a cell phone and $1.5 \mathrm{~h}$ per day using the computer; approximately $43 \%$ of their time on the computer is spent interacting with 
others (social networking, instant messaging, e-mailing; Rideout et al. 2010). In 2010, the Health Behaviour in School-aged Children (HBSC) study in 43 countries across Europe and North America showed that on average $28 \%$ of 11-year olds, $46 \%$ of 13 -year olds, and $57 \%$ of 15 -year olds reported daily EMC with friends (Currie et al. 2012).

Previous research has shown that EMC is associated with adolescent substance use. For example, more frequent mobile phone use and text messaging, e-mailing, and instant messaging have been associated with earlier and heavier substance use among adolescents in different countries (e.g., Leena et al. 2005; Ohannessian 2009; Osaki et al. 2012). Related to this, the amount of screen-based media (SBM) use was consistently and positively correlated with tobacco use, alcohol use, and getting drunk across 10 countries in Europe and North America (e.g., Iannotti et al. 2009a, b; Nelson and Gordon-Larsen 2006).

In spite of these findings, it remains unclear how the associations between EMC and substance use should be interpreted. On the one hand, since adolescents use EMC primarily to interact and maintain relationships with already familiar offline peers (Kraut et al. 2002; Subrahmanyam and Greenfield 2008), these associations may reflect already established associations between offline interactions and adolescent substance use (e.g., Chassin et al. 2009; Kokkevi et al. 2007; Kuntsche et al. 2009a). On the other hand, there may be unique associations of EMC with adolescent substance. EMC is frequently used to display engagement in substance use (e.g., texting about or posting pictures of partying and drinking; Loss et al. 2013; Moreno et al. 2009), and exposure to online displays of substance use by peers has been associated with adolescents' own substance use (e.g., Huang et al. 2014; Litt and Stock 2011; Stoddard et al. 2012). Accordingly, unique associations between EMC and adolescent substance use are expected over and beyond associations with offline interactions. Furthermore, EMC may strengthen the existing associations of offline interactions with substance use, due to an increase in exposure to peers' displays of substance use via EMC. In contrast, however, EMC could also weaken these associations, due to a decrease in offline interactions as a result of more EMC, resulting in less opportunity to use substances (Kuntsche et al. 2009a).

Given this gap in the literature, the current study examined the unique associations of EMC with adolescent tobacco, alcohol, and cannabis use over and beyond the associations of offline interactions with these substance use behaviors. Two sources of offline interactions relevant for adolescent substance use were distinguished: friends and classmates.

First, face-to-face (FTF) interactions with friends after school and in the evening were included. Behaviorally based theories of influence suggest that adolescents emulate the behaviors of their friends following friends' social reinforcements (Piehler 2011; Prinstein and Dodge 2008). In line with this, it is well established that hanging out with friends is related to adolescent substance use (Branstetter et al. 2011; Chassin et al. 2009; Duncan et al. 2006; Rai et al. 2003). Frequent FTF interactions with friends in the evening in particular were strongly associated with various forms of substance use (Kuntsche et al. 2009a).

Second, adolescent substance use is known to be affected by the level of exposure to peers who engage in such behaviors (e.g., Ennett et al. 2006; Hartup 2005). An important context in this regard is the classroom. Adolescents spend many hours a day interacting with classmates and thus may be frequently exposed to classmates' displays of substance use behavior. In this regard, displays refer to both the actual engagement in substance use as well as the visual or verbal presentation of prior substance use. Identity-based theories of influence (e.g., Piehler 2011; Prinstein and Dodge 2008) suggest that adolescents tend to conform to the average level of classroom substance use to be accepted and to avoid rejection by their classmates. Thus, high average classroom substance use is likely to encourage adolescents to also engage in substance use behavior themselves. Indeed, studies have shown that adolescents tend to be similar in substance use to their classmates (Chassin et al. 2009; Hussong 2002; SimonsMorton and Farhat 2010).

In summary, the current study examined the associations of EMC with friends with adolescent substance use (tobacco, alcohol, and cannabis), over and beyond the associations of FTF interactions with friends and average classroom substance use. Based on the majority of former research, it was expected that more EMC would be uniquely associated with more adolescent substance use. Further, it was hypothesized that EMC would strengthen the associations of FTF interactions with friends as well as average classroom substance use with individual substance use, due to the increased exposure to peers' displays of such behaviors via EMC.

\section{Methods}

\section{Participants}

Data were collected in The Netherlands as part of the crossnational 2009/2010 HBSC study. A full description of this study and its methods can be found elsewhere (Roberts et al. 2009). Consent procedures required by ethical and legal authorities for this type of survey were followed.

A random, stratified-by-urbanity sample of schools was drawn to ensure population representativeness. In total, 68 
of the 143 approached secondary schools participated in the study ( $48 \%$ response rate). For each school, one class per grade was randomly selected for grades $7-10$. The average response rate within classrooms was $93 \%$; the main reason for non-participation was illness. The final sample included 5,642 adolescents $\left(M_{\text {age }}=14.29\right.$; $\mathrm{SD}=1.26 ; 49.2 \%$ boys). Most participants were of Dutch origin $(81.5 \%, n=4,597)$.

\section{Measures}

\section{Substance use}

Participants rated how often they used tobacco, alcohol, and cannabis in the last 4 weeks. Tobacco and cannabis use were rated on a 7 -point ordinal scale $(1=$ never, $2=1-2$ times, $3=3-5$ times, $4=6-9$ times, $5=10-19$ times, $6=20-39$ times, $7=40$ times or more). Since alcohol consumption is generally more normative among adolescents than tobacco and cannabis use, alcohol use was rated on a wider 14-point ordinal scale $(1-11=0-10$ times, $12=11-19$ times, $13=20-39$ times, $14=40$ times or more) to allow for more differentiation in alcohol use between adolescents.

\section{Electronic media communication (EMC)}

To assess EMC with friends, adolescents were asked: How often do you talk to your friend(s) on the phone, communicate with them via instant messaging, or send them text messages or e-mails? Participants answered on a 5-point ordinal scale $(1=$ rarely or never, $2=1$ or 2 days a week, $3=3$ or 4 days a week, $4=5$ or 6 days a week, $5=$ every day).

\section{Face-to-face (FTF) interactions}

Participants rated on a 6-point ratio scale ( $0-5$ days) how many days per week they usually spend time with friends after school (FTF day). They also rated on an 8-point ratio scale (0-7 evenings) how many evenings per week they usually spend out with friends (FTF evening).

\section{Average classroom substance use}

The average level of classroom substance use was estimated by taking the average of the substance use behaviors reported by the odd numbered students per classroom $(n=2,819)$, while the analyses were run on the remaining even numbered students $(n=2,817)$. This splitting of the sample was necessary to control for endogenous feedback (mutual influence). There were no significant differences in age or any of the outcomes between the two subsamples $(\Delta M=0.002-0.062)$.

\section{Computer and internet use}

Since both EMC and substance use may be affected by the degree of computer and internet use (e.g., Kuntsche et al. 2009a), weekly computer and internet use were used as control variables. To assess general computer use (online and offline), adolescents were asked "How many hours per day of your free time do you usually use the computer for chatting online, internet, e-mailing, homework, etc.?" A score for weekly computer use was computed by multiplying this number by seven. To assess a more detailed account of actual time spent online, adolescents were asked: "How many days per week do you use the internet?", and "On a day that you use the internet, how many hours do you usually spend on the internet?" A score for weekly internet use was computed by multiplying participants' answers to these two questions.

\section{Procedure}

Data were collected through an anonymous paper-andpencil questionnaire during a 45- to 60-min classroom session. Participants were informed of the goal of the study and received instructions on how to fill out the questionnaire. The confidentiality and anonymity of their answers were clearly explained. A research assistant was present to make sure instructions were followed and to answer questions.

\section{Analysis strategy}

Given the two-level hierarchical structure of the data (participants nested within classrooms), multilevel analyses were run in Mplus 7 (Muthén and Muthén 2012). Multilevel modeling was warranted based on the ICCs and the design effect (DE) estimates (see Table 1). All predictors were grand mean centered. Modeled (explained) variance was calculated using the formulae by Snijders and Bosker (1994) to diminish the possibility of negative $R^{2}$. Models were estimated using maximum likelihood estimation with robust standard errors and model fit was assessed with $\chi^{2}$ log-likelihood difference tests (Hox 2010).

Model 1 was an intercept-only model. Proportions of within- and between-level variance (intraclass correlations) at the classroom level were calculated to assess if variability in substance use was associated with individual or between-classroom differences. Next, control and predictor variables were added in subsequent models and the significance of the fixed effects of the predictors on substance 
Table 1 Descriptive statistics for predictor and dependent variables, correlational coefficients with predictor variables, and intraclass correlations (ICCs) and design effect estimates (DEs) for classroom level by dependent variables (The Netherlands, 2009)

\begin{tabular}{|c|c|c|c|c|c|c|c|c|c|c|}
\hline \multirow[t]{2}{*}{ Variable } & \multirow[t]{2}{*}{$n$} & \multirow[t]{2}{*}{$M$} & \multirow[t]{2}{*}{$\mathrm{SD}$} & \multirow[t]{2}{*}{ Skewness ${ }^{\mathrm{b}}$} & \multirow[t]{2}{*}{ Kurtosis $^{\mathrm{b}}$} & \multicolumn{4}{|c|}{ Correlations $\mathrm{r}$ with predictor variables $\mathrm{s}^{\mathrm{a}}$} & \multirow{2}{*}{$\begin{array}{l}\text { Intraclass correlations } \rho \\
(\mathrm{DE}) \\
\text { Classroom level }\end{array}$} \\
\hline & & & & & & EMC & $\begin{array}{l}\text { FTF } \\
\text { day }\end{array}$ & $\begin{array}{l}\text { FTF } \\
\text { evening }\end{array}$ & $\begin{array}{l}\text { Classroom substance } \\
\text { use }\end{array}$ & \\
\hline \multicolumn{11}{|c|}{ Predictor variables } \\
\hline EMC & 2,793 & 3.63 & 1.37 & -0.51 & -1.06 & & & & & \\
\hline FTF day & 2,784 & 3.30 & 1.54 & 0.31 & -0.85 & 0.20 & & & & \\
\hline $\begin{array}{l}\text { FTF } \\
\text { evening }\end{array}$ & 2,770 & 2.86 & 1.71 & 1.12 & 0.97 & 0.31 & 0.40 & & & \\
\hline \multicolumn{11}{|c|}{ Dependent variables } \\
\hline Tobacco & 2,794 & 1.57 & 1.54 & 2.76 & 6.23 & 0.17 & 0.22 & 0.38 & 0.33 & $0.149(2.43)$ \\
\hline Alcohol & 2,752 & 2.57 & 2.97 & 2.27 & 4.41 & 0.24 & 0.13 & 0.37 & 0.46 & $0.273(3.57)$ \\
\hline Cannabis & 2,768 & 1.10 & 0.58 & 7.34 & 59.55 & 0.10 & 0.12 & 0.23 & 0.17 & $0.077(1.73)$ \\
\hline
\end{tabular}

${ }^{a}$ All correlation coefficients significant at $p<0.01$, unless otherwise specified. A Bonferroni correction was applied to the correlations between predictor and dependent variables to control for FWER in multiple comparisons $(p<\alpha / 12)$

b $\mathrm{SE}_{S}=0.046-0.047, \mathrm{SE}_{K}=0.093-0.094$

use were examined. In Model 2, the Level 1 control variables age, sex, weekly computer use, and weekly internet use were added. In Model 3, EMC was added as a predictor at Level 1. In Model 4, FTF interactions (day and evening) were added at Level 1. In Model 5, average classroom substance use was added as a predictor at Level 2. To test whether the parameter estimates of EMC, FTF interactions, and average classroom substance use varied significantly from each other, equality constraints between estimates were added one by one. A Wald $\chi^{2}$ test was conducted to analyze the significance of each equality constraint separately. Finally, in Model 6, the Level 1 interactions of EMC with FTF day and FTF evening and the cross-level interaction of EMC with average classroom substance use were added.

\section{Results}

Preliminary analysis

Descriptive statistics and correlations are presented in Table 1. The distribution of the substance use behaviors was positively skewed (most adolescents did not engage in them). Table 1 shows that substance use behaviors were significantly and positively correlated with all predictor variables. More EMC, more FTF interactions (day and evening), and a higher average level of classroom substance use were associated with more individual substance use. However, some associations should be interpreted with caution given the small correlation coefficients (i.e., little variance in individual substance use was explained by variance in one of the predictors). Further analysis showed small to moderate positive associations between all three predictors (EMC, FTF day, and FTF evening; see Table 1).

Fixed effects of predictor variables

The fixed effects for the control variables age, computer use, and internet use were excluded from the tables; all estimates were small and non-significant. For each dependent variable, $\chi^{2}$ log-likelihood difference tests showed significant improvements in model fit for all subsequent models indicating that all predictors significantly explained variance (see Tables 2, 3, 4). Use of each substance was significantly and positively associated with EMC, FTF day, FTF evening, and average classroom substance use, except for alcohol use with FTF day.

For tobacco use, all parameter estimates differed significantly from each other, except EMC and FTF day (Wald $\chi^{2}=1.54, p=0.21$ ). EMC was equally strongly associated with tobacco use as FTF day, and less strongly associated with tobacco use than FTF evening and average classroom substance use. For alcohol use, similar results were found; parameter estimates differed significantly from each other except EMC and FTF evening (Wald $\chi^{2}=2.57$, $p=0.11)$. EMC was equally strongly associated with alcohol use as FTF evening, more strongly associated with alcohol use than FTF day, and less strongly associated with alcohol use than average classroom substance use. For cannabis use, again all parameter estimates differed significantly from each other, except EMC and FTF day (Wald $\chi^{2}=0.78, p=0.38$ ). EMC was equally strongly associated with cannabis use as FTF day, and less strongly 
Table 2 Fixed and random parameter estimates for tobacco use (The Netherlands, 2009)

\begin{tabular}{|c|c|c|c|c|c|c|}
\hline & $\begin{array}{l}\text { Model } 1^{\mathrm{a}} \\
B(\mathrm{SE})\end{array}$ & $\begin{array}{l}\text { Model } 2 \\
B \text { (SE) }\end{array}$ & $\begin{array}{l}\text { Model } 3 \\
B \text { (SE) }\end{array}$ & $\begin{array}{l}\text { Model } 4 \\
B \text { (SE) }\end{array}$ & $\begin{array}{l}\text { Model } 5 \\
B \text { (SE) }\end{array}$ & $\begin{array}{l}\text { Model } 6 \\
B \text { (SE) }\end{array}$ \\
\hline \multicolumn{7}{|l|}{ Fixed effects } \\
\hline Intercept $\left(\gamma_{00}\right)$ & $\begin{array}{l}1.603 \\
(0.047) * * *\end{array}$ & $\begin{array}{l}1.291 \\
\quad(0.193)^{* * * *}\end{array}$ & $\begin{array}{l}1.377 \\
(0.249)^{* * * *}\end{array}$ & $\begin{array}{l}1.260 \\
(0.237)^{* * *}\end{array}$ & $\begin{array}{l}1.369 \\
(0.171)^{* * * *}\end{array}$ & $\begin{array}{l}1.388 \\
\quad(0.146) * * *\end{array}$ \\
\hline $\operatorname{Sex}\left(\gamma_{20}\right)^{b}$ & & $-0.005(0.059)$ & $\begin{array}{l}-0.129 \\
\quad(0.062)^{*}\end{array}$ & $0.007(0.060)$ & $0.009(0.059)$ & $-0.007(0.058)$ \\
\hline $\operatorname{EMC}\left(\gamma_{50}\right)$ & & & $\begin{array}{l}0.166 \\
\quad(0.025)^{* * * *}\end{array}$ & $0.047(0.024)$ & $0.051(0.023)^{*}$ & $0.071(0.027)^{* *}$ \\
\hline FTF day $\left(\gamma_{60}\right)$ & & & & $\begin{array}{l}0.081 \\
\quad(0.020)^{* * *}\end{array}$ & $\begin{array}{l}0.089 \\
\quad(0.019) * * *\end{array}$ & $\begin{array}{l}0.091 \\
\quad(0.019) * * *\end{array}$ \\
\hline FTF evening $\left(\gamma_{70}\right)$ & & & & $\begin{array}{l}0.271 \\
\quad(0.029)^{* * *}\end{array}$ & $\begin{array}{l}0.242 \\
\quad(0.027)^{* * *}\end{array}$ & $\begin{array}{l}0.225 \\
\quad(0.026)^{* * *}\end{array}$ \\
\hline Classroom substance use $\left(\gamma_{01}\right)$ & & & & & $\begin{array}{l}0.494 \\
\quad(0.064) * * *\end{array}$ & $\begin{array}{l}0.490 \\
\quad(0.070) * * *\end{array}$ \\
\hline \multicolumn{7}{|l|}{ Interaction effect } \\
\hline FTF day $\times$ EMC $\left(\gamma_{80}\right)$ & & & & & & $0.037(0.013)^{* *}$ \\
\hline FTF evening $\times$ EMC $\left(\gamma_{90}\right)$ & & & & & & $0.041(0.016)^{*}$ \\
\hline $\begin{array}{l}\text { Classroom substance use } \times \text { EMC } \\
\left(\gamma_{71}\right)\end{array}$ & & & & & & $0.080(0.044)$ \\
\hline \multicolumn{7}{|l|}{ Random effects } \\
\hline Participant level $\left(\sigma_{e i j}^{2}\right)$ & $\begin{array}{l}2.033 \\
\quad(0.152)^{* * * *}\end{array}$ & $\begin{array}{l}2.054 \\
\quad(0.155)^{* * * *}\end{array}$ & $\begin{array}{l}2.014 \\
\quad(0.152)^{* * * *}\end{array}$ & $\begin{array}{l}1.825 \\
\quad(0.134) * * *\end{array}$ & $\begin{array}{l}1.829 \\
\quad(0.134)^{* * * *}\end{array}$ & $\begin{array}{l}1.766 \\
\quad(0.153)^{* * * *}\end{array}$ \\
\hline Classroom level $\left(\sigma_{u 0 j}^{2}\right)$ & $\begin{array}{l}0.355 \\
\quad(0.078) * * *\end{array}$ & $\begin{array}{l}0.310 \\
\quad(0.082)^{* * * *}\end{array}$ & $\begin{array}{l}0.292 \\
\quad(0.083) * * *\end{array}$ & $\begin{array}{l}0.183 \\
\quad(0.059)^{* * *}\end{array}$ & $0.045(0.033)$ & $0.054(0.047)$ \\
\hline \multicolumn{7}{|l|}{ Model summary } \\
\hline$\Delta$ Deviance $(\Delta d f)^{\mathrm{c}}$ & $5,092.15(3)$ & $238.41(4)^{* * *}$ & $70.61(1)^{* * *}$ & $203.06(2)^{* * *}$ & $58.65(1)^{* * *}$ & $28.49(5)^{* * *}$ \\
\hline \multicolumn{7}{|l|}{ Explained variance $R^{2}$} \\
\hline Participant level $\left(R_{1}^{2}\right)$ & & 0.010 & 0.157 & 0.159 & 0.215 & \\
\hline Classroom level $\left(R_{2}^{2}\right)$ & & 0.101 & 0.415 & 0.413 & 0.729 & \\
\hline
\end{tabular}

$* p<0.05, * * p<0.01 ; * * * p<0.001$

${ }^{\text {a }}$ Model 1: $\rho_{1}($ participant level $)=85.1 \%, \rho_{2}($ classroom level $)=14.9 \%$

b $1=$ boys, $2=$ girls

${ }^{\mathrm{c}}$ For Model 1, the absolute deviance and $d f$ is provided. For Models 2-6, the deviance of each model was compared to/subtracted from the previous one

associated with cannabis use than FTF evening and average classroom substance use. Comparing the standardized parameter estimates for EMC in Model 5 between the three substances (results not displayed in the tables) showed that the effect of EMC was significantly stronger for alcohol $\left(\beta=0.15, \mathrm{SE}_{\beta}=0.02\right)$ than for tobacco $(\beta=0.05$, $\left.\mathrm{SE}_{\beta}=0.02, t(5,180)=3.33, p<0.001\right)$ or cannabis use $\left(\beta=0.06, \mathrm{SE}_{\beta}=0.02, t(5,160)=2.79, p<0.01\right)$.

Interaction effects

There were four significant interactions: FTF day by EMC for tobacco use, FTF evening by EMC for tobacco use and cannabis use, and average classroom use by EMC for alcohol use (see Model 6 in Tables 2, 3, 4). These four interactions are explained below. To examine the interactions, simple slopes for the associations of FTF day, FTF evening, and average classroom substance use with individual substance use were tested at low (lowest grand mean centered value $=-2.63$ ), moderate $(0)$, and high (highest grand mean centered value $=1.37$ ) levels of EMC (see Figs. 1, 2, 3, 4). Simple slopes were significant at $p<0.05$ with some exceptions as indicated below.

First, the interaction effect of EMC by FTF day on tobacco use (see Fig. 1) indicated that the association between FTF day and tobacco use was stronger at high levels of EMC $\left(B=0.14, \mathrm{SE}_{B}=0.03, p<0.001\right)$ than at moderate levels of $\mathrm{EMC} \quad\left(B=0.09, \quad \mathrm{SE}_{B}=0.02\right.$, $p<0.001)$, while this association was not significant at low levels of EMC $\left(B=-0.01, \mathrm{SE}_{B}=0.03, p=0.84\right)$. 


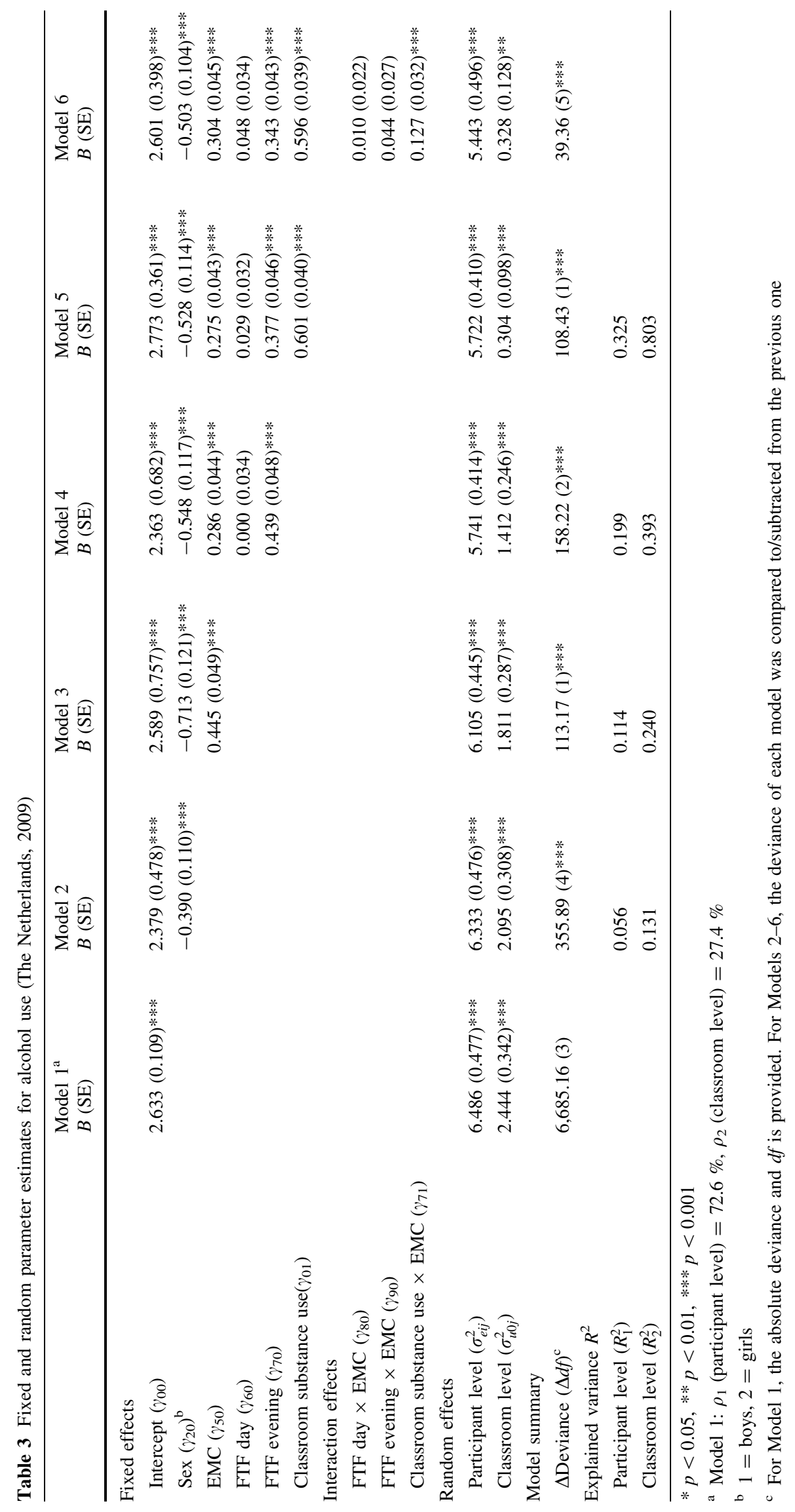




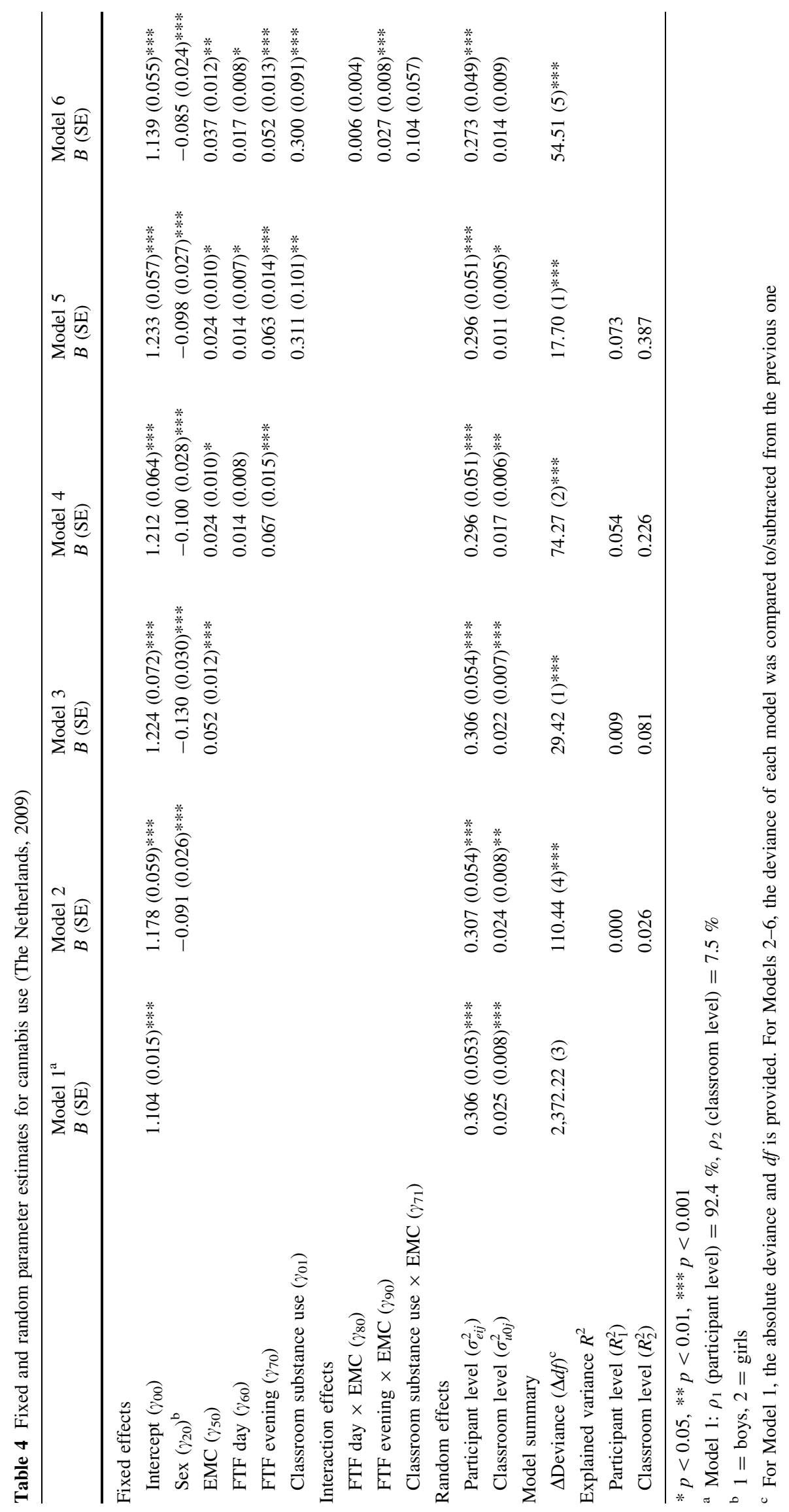




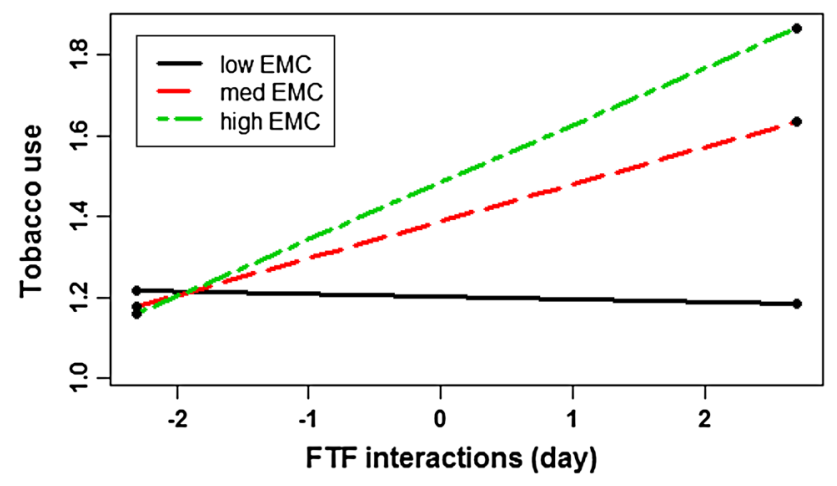

Fig. 1 Interaction tobacco use (The Netherlands, 2009) Simple slopes for face-to-face (FTF) day by electronic media communication (EMC)

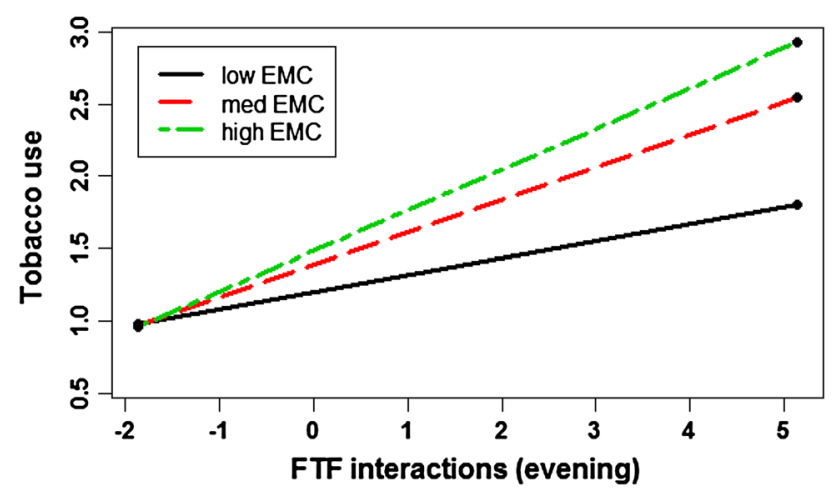

Fig. 2 Interaction tobacco use (The Netherlands, 2009) Simple slopes for face-to-face (FTF) evening by electronic media communication (EMC)

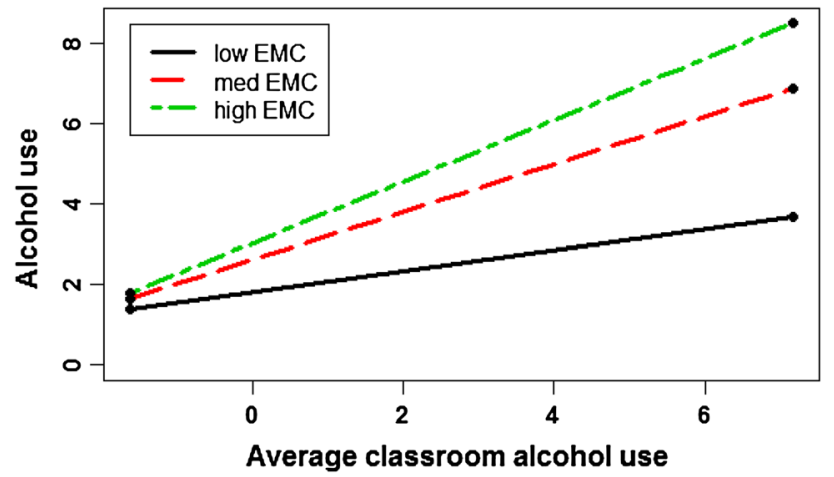

Fig. 3 Cross-level interaction alcohol use (The Netherlands, 2009) Simple slopes for average classroom alcohol use (ALC) by electronic media communication (EMC)

Second, the interaction effect of EMC by FTF evening on tobacco use (see Fig. 2) showed that the association between FTF evening and tobacco use was stronger at high levels of $\operatorname{EMC~}\left(B=0.28, \mathrm{SE}_{B}=0.04, p<0.001\right)$ than at moderate $\left(B=0.22, \mathrm{SE}_{B}=0.03, p<0.001\right)$ or low levels

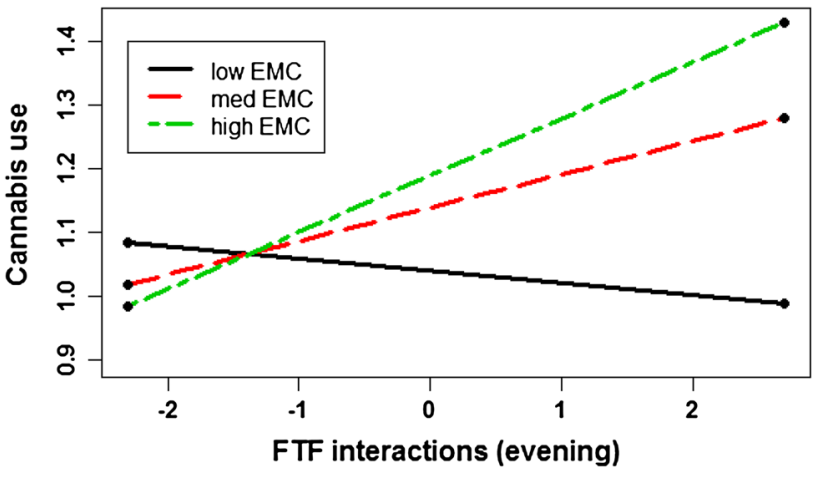

Fig. 4 Interaction cannabis use (The Netherlands, 2009) Simple slopes for face-to-face (FTF) evening by electronic media communication (EMC)

of EMC $\left(B=0.12, \mathrm{SE}_{B}=0.05, p<0.05\right)$.Third, the interaction effect of EMC by average classroom alcohol use on individual alcohol use (see Fig. 3) showed that the association between classroom and individual alcohol use was stronger at high levels of EMC $(B=0.77$, $\left.\mathrm{SE}_{B}=0.05, p<0.001\right)$ than at moderate $(B=0.60$, $\left.\mathrm{SE}_{B}=0.04, p<0.001\right)$ or low levels of EMC $(B=0.26$, $\left.\mathrm{SE}_{B}=0.10, p<0.05\right)$. Fourth and finally, the interaction effect of EMC by FTF evening on cannabis use (see Fig. 4) demonstrated that the association between FTF evening and cannabis use was stronger at high levels of EMC $\left(B=0.09, \mathrm{SE}_{B}=0.02, p<0.001\right)$ than at moderate levels of EMC $\left(B=0.05, \mathrm{SE}_{B}=0.01, p<0.001\right)$. FTF evening was not associated with cannabis use at low levels of EMC $\left(B=-0.02, \mathrm{SE}_{B}=0.02, p=0.34\right)$.

\section{Discussion}

This study showed that higher levels of EMC were associated with higher levels of adolescent substance use, predominantly for alcohol use. EMC explained unique substance use variance over and beyond FTF interactions and average classroom substance use. These findings are consistent with previous research positively linking EMC to adolescent substance use (e.g., Leena et al. 2005; Ohannessian 2009; Osaki et al. 2012). Further, EMC strengthened the positive associations of FTF interactions after school with tobacco use, FTF interactions in the evening with tobacco and cannabis use, and average classroom alcohol use with individual alcohol use. These findings are consistent with the idea that EMC is complementary to rather than substituting for FTF interactions (Kraut et al. 2002; Kuntsche et al. 2009b).

Various explanations can be provided for the positive main and interaction effects of EMC on adolescent substance use. A first explanation is that adolescents who use 
EMC frequently also have frequent offline FTF interactions with (the same) peers (Kraut et al. 2002; Subrahmanyam and Greenfield 2008); they are thus highly socially active and outgoing, and they use EMC to communicate with peers about where and when to meet and what to do offline (Kuntsche et al. 2009b; Subrahmanyam and Greenfield 2008). More EMC is thus associated with more FTF interactions. As a consequence, their own substance use likely increases, given the well-established fact that adolescents often engage in substance use in the presence of peers and the fact that peer substance use predicts adolescents own substance use (e.g., Branstetter et al. 2011; Chassin et al. 2009; Duncan et al. 2006; Rai et al. 2003). However, the associations between EMC and adolescent substance use should not be interpreted as solely a result of frequent FTF interactions. Although results showed a positive association between EMC and FTF interactions and although parameter estimates of EMC decreased after including FTF interactions, the unique associations of EMC with adolescent substance use remained significant for all three substances after including FTF interactions. This implies that the associations between EMC and adolescent substance use must be explained by other processes as well.

This explanation may be found in the content of adolescents' and their peers' EMC, especially for alcohol use. It is well established that adolescents use EMC to display engagement in substance use and that the most frequently displayed substance is alcohol (e.g., texting about or posting pictures of partying and drinking; Loss et al. 2013; Moreno et al. 2009). Such online displays of substance use are typically presented with a positive connotation (e.g., sociable, fun, and daring) rather than raising health concerns, and are intended to make a desired impression on peers. Since adolescents' online displays of substance use usually receive positive feedback from peers, the perceived attractiveness of substance use may enhance (Loss et al. 2013). Consequently, adolescents' own substance use likely increases to match that of their peers. This explanation is consistent with previous research showing a positive link between peers' online displays of substance use and adolescents own substance use (e.g., Huang et al. 2014; Litt and Stock 2011; Stoddard et al. 2012).

Although the content of participants' EMC was not inquired in this study, the significant interaction of EMC by average classroom alcohol use suggests that adolescents indeed communicate about their drinking via EMC; participants in classrooms with high levels of alcohol use who rarely used EMC reported significantly lower levels of alcohol use than participants from similar classrooms who used EMC frequently. Assuming that most of adolescents' online peers are from their classroom and that adolescents' EMC is thus predominantly with classmates, these findings support the aforementioned explanation concerning the substance use-related content of participants' EMC.

Comparing the standardized estimates of EMC across the three substances, not surprisingly associations were the strongest for drinking. Alcohol use is more normative and acceptable than tobacco and cannabis use (Morgan et al. 2010), and subsequently the most displayed and communicated of the three substances (Loss et al. 2013; Moreno et al. 2009). The increased stigma surrounding tobacco and (illegal) cannabis use may make it less likely for adolescents to communicate about these behaviors, as this would potentially harm the impression others have of them (Morgan et al. 2010; Stoddard et al. 2012). In addition, alcohol consumption is frequently presented and perceived as an enjoyable social activity. Compared to smoking, for example, adolescents are more likely to drink alcohol together with others to celebrate an event (Huang et al. 2014; Loss et al. 2013). The social and rewarding nature of alcohol use, compared to tobacco and cannabis, likely also explains the differences in the parameter estimates for EMC.

There are several limitations specific to this study. First, due to the cross-sectional and correlational design, no causal inferences can be made. It may be that adolescents who are already at risk for substance use are also at risk for higher levels of EMC (Leena et al. 2005; Osaki et al. 2012), or it may be that adolescents with high levels of substance use are more drawn to EMC because their substance use enhances their social connectedness and standing among peers (Killeya-Jones et al. 2007). Further, it may be that adolescents specifically select peers who already have similar levels of substance use to communicate with via EMC (Stoddard et al. 2012).

Second, the findings may vary as a function of specific details of participants' EMC, such as the actual content of their EMC, when and where participants use EMC, how and what form of EMC is used (e.g., instant messaging vs. social networking), and with whom they communicate via EMC (e.g., an existing offline friend or not). Since characteristics of EMC are very much time-related, the current study should be replicated to see if and how these associations may have changed over the years. Substantial (qualitative) differences are, however, not expected given the findings from similar more recent studies (e.g., Huang et al. 2014; Loss et al. 2013).

Future research would also benefit from a more detailed account of adolescents' EMC. For instance, future research should investigate associations between substance use and social networking, which has become a vital part of EMC and which, unfortunately, was not assessed in the 2009/2010 HBSC study. In addition, future measures of EMC should be adapted to accommodate present day frequency of EMC. Although a considerable portion of the 
2009/2010 sample did not use EMC on a daily basis, it is likely to assume that EMC use increased over the years with many adolescents now using it multiple times a day.

More general limitations also apply. The self-reported nature of all measures may have led to biased estimates. However, adolescents are fairly accurate in their selfreported tobacco and cannabis use (e.g., Harrison et al. 2007). Further, due to the large sample used in the current study, significance is easily reached. Therefore, the significant though small associations of EMC with tobacco and cannabis use should be interpreted with caution. Finally, sample characteristics may limit the generalizability of the findings to other countries, although associations of EMC and SBM use with substance use seem not to vary much across countries (e.g., Iannotti et al. 2009b; Leena et al. 2005). Thus, similar findings may be expected in other countries. A direction for future research is to investigate the associations in multiple diverse countries and to use other sources of adolescent substance use such as peer reports.

\section{Conclusion and practical implications}

In summary, this study demonstrated that EMC is uniquely associated with adolescent substance use, predominantly with alcohol use, over and beyond the associations of FTF interactions and average classroom substance use with individual substance use. Moreover, EMC strengthened several of these associations. These findings imply that EMC and other online behaviors should not be left unnoticed to fully understand and prevent adolescent substance use. Prevention efforts should take into account the potential negative consequences of online displays of substance use and should include information on the potential inaccuracy and one-sidedness of peers' online reports of substance use.

\section{References}

Branstetter SA, Low S, Furman W (2011) The influence of parents and friends on adolescent substance use: a multidimensional approach. J Subst Use 16:150-160

Brechwald WA, Prinstein MJ (2011) Beyond homophily: a decade of advances in understanding peer influence processes. J Res Adolesc 21:166-179

Brown BB, Larson J (2009) Peer relationships in adolescence. In: Lerner R, Steinberg L (eds) Handbook of adolescent psychology, 3rd edn. Wiley, Hoboken, pp 74-103

Chassin L, Hussong A, Beltran I (2009) Adolescent substance use. In: Lerner R, Steinberg L (eds) Handbook of adolescent psychology, 3rd edn. Wiley, Hoboken, pp 723-763

Currie C, Zanotti C, Morgan A, Currie D, de Looze M, Roberts C, Samdel O, Smith ORF, Barnekow V (2012) Social determinants of health and well-being among young people: health behaviour in school-aged children (HBSC) study: international report from the 2009/2010 survey, World Health Organization

Dijkstra JK, Veenstra R (2011) Peer relations. In: Brown BB, Prinstein MJ (eds) Encyclopedia of Adolescence. Elsevier, New York, pp 255-259

Duncan SC, Duncan TE, Strycker LA (2006) Alcohol use from ages 9 to 16: a cohort-sequential latent growth model. Drug Alcohol Depend 81:71-81

Ennett ST, Bauman KE, Hussong A, Faris R, Foshee VA, Cai Li (2006) The peer context of adolescent substance use: findings from social network analysis. J Res Adolesc 16:159-186

Harrison LD, Martin SS, Enev T, Harrington D (2007) Comparing drug testingand self-report of drug use among youths and young adults in the general population. In: Rockville, MD (ed) substance abuse and mental health services administration, Office of Applied Studies

Hartup WW (2005) Peer interactions: what causes what? J Abnorm Child Psychol 33:387-394

Hox JJ (2010) Multilevel analysis: techniques and applications, 2nd edn. Routledge, New York

Huang GC, Unger JB, Soto D, Fujimoto K, Pentz MA, Jordan-Marsh $M$ et al (2014) Peer influences: the impact of online and offline friendship networks on adolescent smoking and alcohol use. J Adolesc Health 54:508-514

Hussong AM (2002) Differentiating peer contexts and risk for adolescent substance use. J Youth Adolesc 31:207-220

Iannotti RJ, Janssen I, Haug E, Kololo H, Annaheim B, Borraccino A, The HBSC Physical Activity Focus Group (2009) Interrelationships of adolescent physical activity, screen-based sedentary behaviour, and social and psychological health. Int J Public Health 54:191-198

Iannotti RJ, Kogan MD, Janssen I, Boyce WF (2009) Patterns of adolescent physical activity, screen-based media use, and positive and negative health indicators in the US and Canada. J Adolesc Health 44:493-499

Killeya-Jones LA, Nakajima R, Costanzo PR (2007) Peer standing and substance use in early-adolescent grade-level networks: a short-term longitudinal study. Prev Sci 8:11-23

Kokkevi AE, Arapaki AA, Richardson C, Florescu S, Kuzman M, Stergar E (2007) Furtherinvestigation of psychological and environmental correlates of substance use in adolescence in six European countries. Drug Alcohol Depend 88:308-312

Kraut R, Kiesler S, Boneva B, Cummings J, Helgeson V, Crawford A (2002) Internet paradox revisited. J Soc Issues 58:49-74

Kuntsche E, Simons-Morton B, ter Bogt T, Sánchez Queija I, Muñoz Tinoco V, Gaspar de Matos M, Santinello M, Lenzi M, The HBSC Peer Culture Focus Group (2009) Electronic media communication with friends from 2002 to 2006 and links to faceto-face contacts in adolescence: an HBSC study in 31 European and North American countries and regions. Int J Public Health 54:243-250

Kuntsche E, Simons-Morton B, Fotiou A, ter Bogt T, Kokkevi A (2009) Decrease in adolescent cannabis use from 2002 to 2006 and links to evenings out with friends in 31 European and North American countries and regions. Arch Pediatr Adolesc Med 163:119-125

Leena K, Tomi L, Arja R (2005) Intensity of mobile phone use and health compromising behaviours. How is information and communication technology connected to health-related lifestyle in adolescence? J Adolesc 28:35-47

Lenhart A (2012) Teens, smartphones, and texting. Pew Research Center's Internet and American Life Project. http://pewinternet. org/Reports/2012/Teens-and-smartphones.aspx

Lenhart A, Madden M (2007). Pew internet project data memo: 55\% of online teens use social networks and $55 \%$ have created online profiles. Pew Research Center's Internet and American Life 
Project. http://www.pewinternet.org/2007/01/07/social-networkingwebsites-and-teens/

Litt DM, Stock ML (2011) Adolescent alcohol-related risk cognitions: the roles of social norms and social networking sites. Psychol Addict Behav 25:708-713

Loss J, Lindacher V, Curbach J (2013) Do social networking sites enhance the attractiveness of risky health behavior?. Impression management in adolescents' communication on Facebook and its ethical implications, Public Health Issues

Moreno MA, Parks MR, Zimmerman FJ, Brito TE, Christakis DA (2009) Display of health risk behaviors on Myspace by adolescents. Arch Pediatr Adolesc Med 163:27-34

Morgan EM, Snelson C, Elison-Bowers P (2010) Image and video disclosure of substance use on social media websites. Comput Hum Behav 26:1405-1411

Nelson MD, Gordon-Larsen P (2006) Physical activity and sedentary behavior patterns are associated with selected adolescent health risk behaviors. Pediatrics 117:1281-1290

Muthén LK, Muthén BO (2012) Mplus User's Guide, 7th edn. Muthén and Muthén, Los Angeles

Ohannessian CM (2009) Does technology use moderate the relationship between parental alcoholism and adolescent alcohol and cigarette use? Addict Behav 34:606-609

Osaki Y, Ohida T, Kanda H, Kaneita Y, Kishimoto T (2012) Mobile phone use does not discourage adolescent smoking in Japan. Asian Pac J Cancer Prev 13:1011-1014

Piehler TF (2011) Peer influence. In: Brown BB, Prinstein MJ (eds) Encyclopedia of adolescence. Elsevier, New York, pp 249-254

Prinstein MJ, Dodge KA (2008) Current issues in peer influence research. In: Prinstein MJ, Dodge KA (eds) Understanding peer influence in children and adolescents. Guilford Press, New York, pp 3-13
Purcell K (2013) 10 things to know about how teens use technology. Pew Research Center's Internet and American Life Project. http://www.pewinternet.org/2013/07/10/10-things-to-know-abouthow-teens-use-technology/

Rai AA, Stanton B, Wu Y, Li X, Galbraith J, Cottrell L et al (2003) Relative influences of perceived parental monitoring and perceived peer involvement on adolescent risk behaviors. An analysis of six cross-sectional data sets. J Adolesc Health 33:108-118

Rideout VJ, Foehr UG, Roberts DF (2010) Generation M $^{2}$ : Media in the lives of 8- to 18-year-olds, Kaiser Family Foundation. http:// kff.org/other/report/generation-m2-media-in-the-lives-of-8-to-18year-olds/

Roberts C, Freeman J, Samdal O, Schnohr CW, de Looze ME, Nic Gabhainn S, Iannotti R, Rasmussen M (2009) The Health Behaviour in School-aged Children (HBSC) study: methodological developments and current tensions. Int $\mathbf{J}$ Public Health 54:140-150

Simons-Morton BG, Farhat T (2010) Recent findings on peer group influences on adolescent smoking. J Prim Prev 31:191-208

Snijders TAB, Bosker RJ (1994) Modeled variance in two-level models. J Sociol Methods Res 22:342-363

Stoddard SA, Bauermeister JA, Gordon-Messer D, Johns M, Zimmerman MA (2012) Permissive norms and young adults' alcohol and marijuana use: the role of online communities. J Stud Alcohol Drugs 73:968-975

Subrahmanyam K, Greenfield P (2008) Online communication and adolescent relationships. Future Child 18:119-146

Valkenburg PM, Peter J (2010) Online communication among adolescents: an integrated model of its attraction, opportunities, and risks. J Adolesc Health 48:121-127 